\title{
Primary neuroendocrine breast carcinoma: a case report and literature review*
}

\author{
Carcinoma neuroendócrino primário da mama: relato de caso e revisão da literatura
}

Maria Helena Valentim ${ }^{1}$, Vanessa Monteiro ${ }^{2}$, José Carlos Marques ${ }^{3}$

Valentim MH, Monteiro V, Marques JC. Primary neuroendocrine breast carcinoma: a case report and literature review. Radiol Bras. 2014 Mar/ Abr;47(2):125-127.

Abstract The authors present a case of a neuroendocrine carcinoma in an asymptomatic 75-year-old woman, detected in routine breast screening. The lesion was visible at mammography as a well circumscribed, medium density nodule, with no associated microcalcifications, and at ultrasonography as a hypoechoic nodule, with irregular shape and ill-defined margins. Magnetic resonance imaging revealed findings consistent with malignancy.

Keywords: Carcinoma; Neuroendocrine; Breast; Imaging.

Resu mo Os autores apresentam um caso de carcinoma neuroendócrino numa mulher de 75 anos assintomática detectado em estudo imaginológico mamário de rotina. A lesão apresentava-se na mamografia como nódulo bem circunscrito de média densidade, sem microcalcificações associadas e ecograficamente como nódulo hipoecogênico de morfologia irregular e limites mal definidos. Na ressonância magnética mamária as características da lesão eram concordantes com malignidade.

Unitermos: Carcinoma; Neuroendócrino; Mama; Imaginologia.

\section{INTRODUCTION}

Neuroendocrine carcinomas are rare malignant tumors which, in most of cases, are located in the lungs and gastrointestinal tract. Primary location of such tumors in the breast is extremely rare, corresponding to less than $0.1 \%$ of all breast tumors ${ }^{(1,2)}$.

Most published studies about neuroendocrine breast carcinoma emphasize anatomopathological findings, with scarce reference to imaging findings ${ }^{(3,4)}$.

The present report describes mammographic, sonographic and magnetic resonance imaging (MRI) findings of a case of asymptomatic, primary neuroendocrine breast carcinoma in a 75-year-old woman.

\section{CASE REPORT}

Mammography detected an ovoid, well defined mass with medium density in the upper-inner quadrant of the left breast in an asymptomatic 75-year-old woman. No associated microcalcifications were observed (Figure 1). At ultrasonography, the mass corresponded to a hypoechogenic, morphologically irregular and ill defined, solid nodule, with no al-

* Study developed at the Radiology Department of Instituto Português de Oncologia de Lisboa Francisco Gentil, Lisbon, Portugal.

1. MD, Radiology Resident, Centro Hospitalar de Lisboa Ocidental, Lisbon, Portugal.

2. MD, Specialist of Radiology, Hospital Beatriz Ângelo, Loures, Portugal.

3. MD, Specialist of Radiology, Graduate Assistant, Instituto Português de Oncologia de Lisboa Francisco Gentil, Lisbon, Portugal.

Mailing Address: Dra. Maria Helena Valentim. Alameda Fernão Lopes, 29, $3^{\circ}$ Dto. Lisbon, Portugal. E-mail: mariahelenavalentim@gmail.com.

Received October 16, 2012. Accepted after revision July 18, 2013. teration of posterior echoes, measuring $19 \mathrm{~mm}$ in its greatest diameter (Figure 2).

Considering the imaging characteristics of the mass, the patient's age range, and the fact that it was a new finding, ultrasonography-guided percutaneous biopsy was performed. Anatomopathological analysis revealed a solid, neuroendocrine carcinoma with a carcinoid-like pattern (Figure 3a), and positive for neuron specific enolase, chromogranin and synaptophysin markers (Figure 3b).
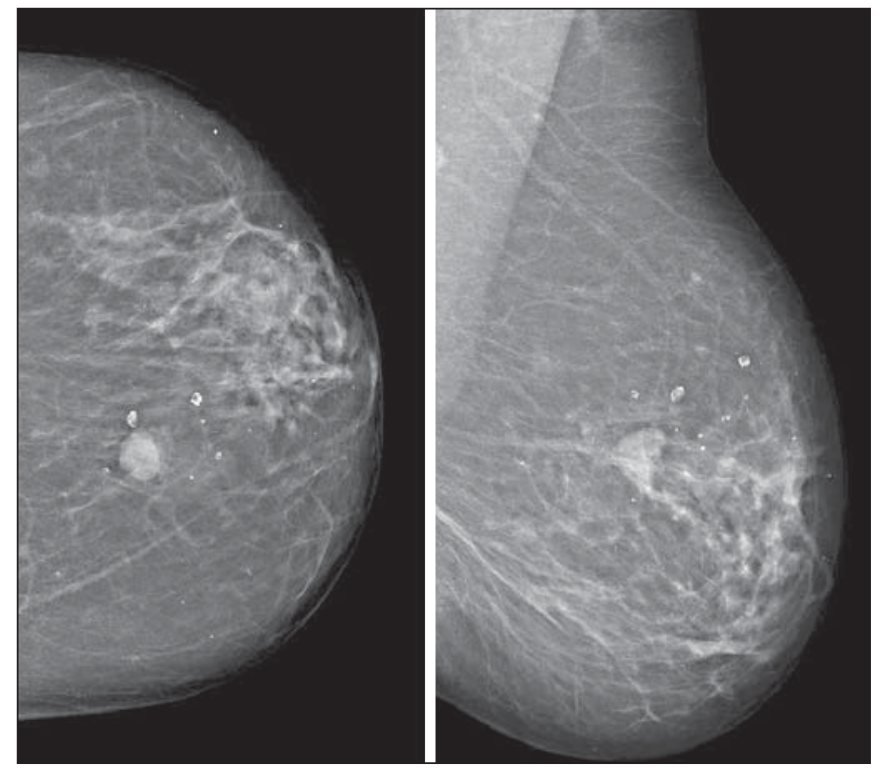

Figure 1. Mammography, craniocaudal and oblique views. An ovoid well defined mass is identified in the upper-inner quadrant of the left breast, with medium density and no associated microcalcifications. 


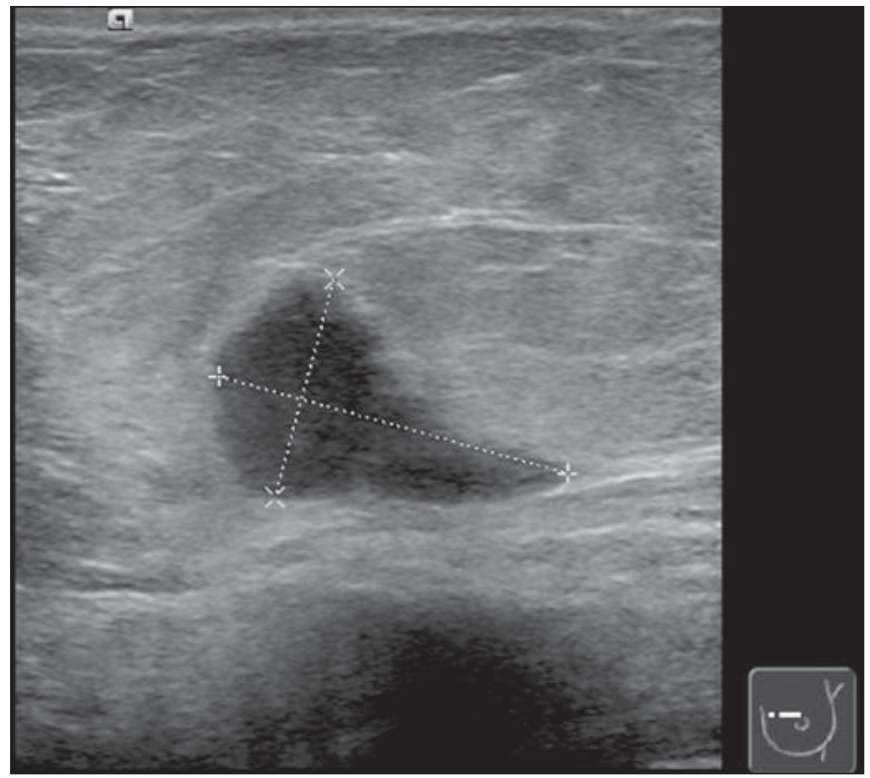

Figure 2. Ultrasonography demonstrated a solid hypoechogenic mass with ill defined contours, without any alteration of posterior echoes, measuring $19 \mathrm{~mm}$ in its largest diameter.
The patient underwent preoperative breast MRI (Figure 4) which confirmed the presence of a hypointense, irregular lesion with $20 \mathrm{~mm}$ in diameter on T2-weighted sequences, with peripheral ring-enhancement after intravenous gadolinium injection, and kinetic curve demonstrating early intense contrast uptake, followed by washout. Additionally, another adjacent, small nodular focus measuring $5 \mathrm{~mm}$ was observed, with comparable features.

In order to rule out a possible extramammary location of neuroendocrine carcinoma, thoracic, abdominal and pelvic computed tomography $(\mathrm{CT})$ was performed, but no other lesion was detected.

The patient underwent conservative surgery and the anatomopathological analysis of the surgical specimen confirmed the diagnosis of a moderately differentiated, multifocal neuroendocrine breast carcinoma.

\section{DISCUSSION}

Neuroendocrine carcinoma primarily located in the breast is an extremely rare entity. Although exact data on its incidence is not available yet, a series developed by Günhan-

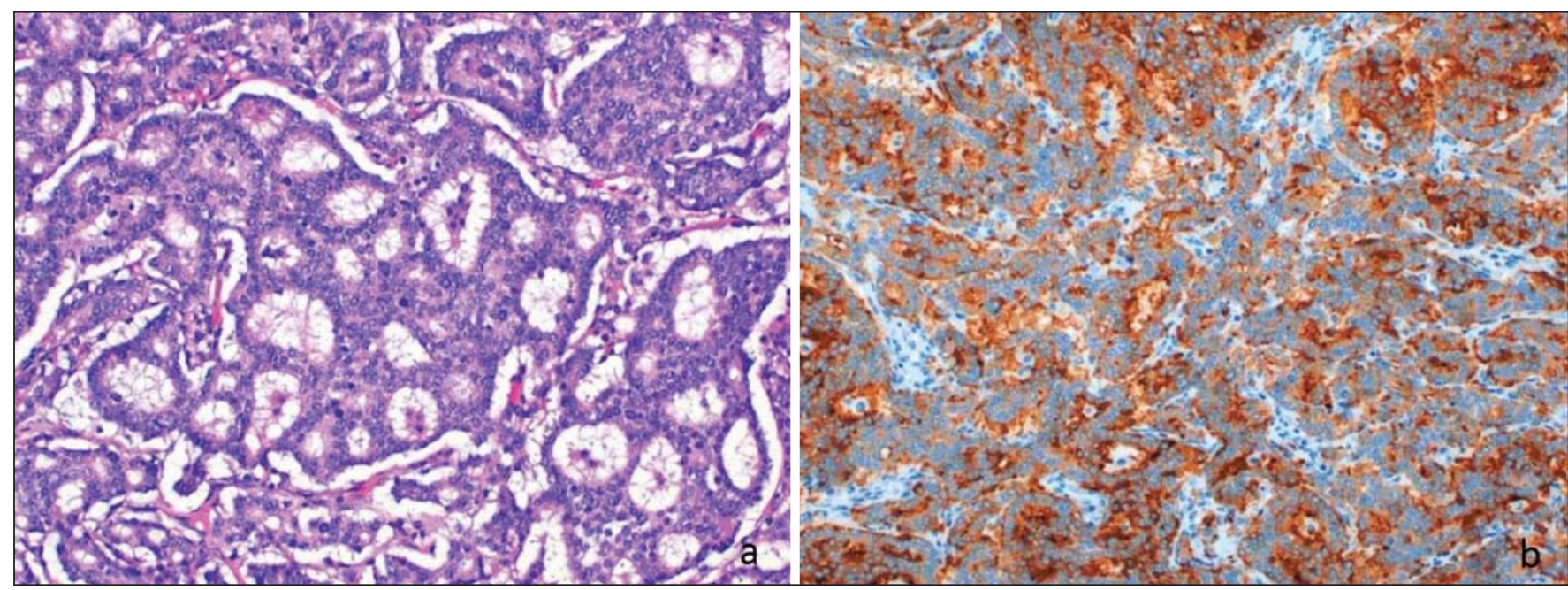

Figure 3. Neuroendocrine tumor with a carcinoid-like pattern. Tumor cells with a rosette pattern of distribution and some cells showing granular eosinophilic cytoplasm (a). Immunohistochemical staining positive for synaptophysin (b).
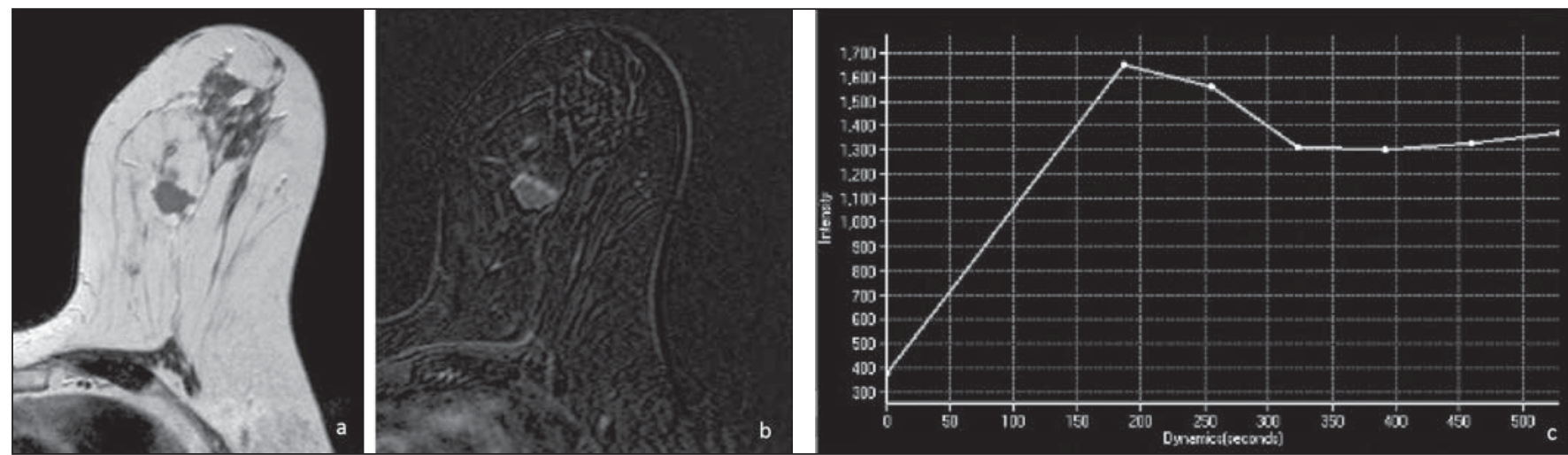

Figure 4. Breast MRI confirming the presence of the lesion in the upper-inner quadrant of the left breast. a: Axial MRI T2-weighted image demonstrating a hypointense lesion with irregular morphology. b: Axial MRI T1-weighted images with fat suppression after gadolinium injection, demonstrating intense, ring-enhancement and identifying another small-sized nodule that is more anteriorly located. c: Kinetic curve of the larger lesion, showing early intense enhancement followed by wash-out, consistent with malignancy. 
Bilgen et al. ${ }^{(5)}$ with 1,845 proved cases of breast tumors reports an incidence as low as $0.27 \%$. Such a tumor presents specific morphological characteristics, expressing neuroendocrine markers on a high percentage $(>50 \%)$ of the cells ${ }^{(3,6)}$. Neuron specific enolase, synaptohysin and chromogranin are generally utilized as markers; the first one is considered as less specific ${ }^{(7)}$. In 2003, the World Health Organization classified neuroendocrine breast carcinomas into three subtypes, as follows: solid, small cell and large cell carcinomas ${ }^{(2,7)}$. However, in a recent revision undertaken in $2012^{(8)}$, neuroendocrine tumors, included in the class of rare epithelial tumors, were subdivided into well differentiated neuroendocrine tumors, poorly differentiated neuroendocrine carcinomas (small cell carcinomas), and carcinomas with neuroendocrine differentiation. In the present case, the tumor was positive for the three neuroendocrine markers, with solid histological subtype and carcinoid-like pattern (the assessment was made prior to the 2012 revision).

The cases of primary neuroendocrine breast carcinoma described in the literature refer mostly to women in the age range between 40 and 70 years ${ }^{(7)}$, and there are some few cases described in male individuals ${ }^{(5)}$.

The diagnosis of primary neuroendocrine breast carcinoma can only be made if an extramammary location is ruled out or an in situ component is demonstrated ${ }^{(3,7,9)}$. In the present case, although an in situ component has not been demonstrated, other locations, namely pulmonary or intestinal, were ruled out at CT.

Neuroendocrine carcinomas do not present any particular imaging finding and, in many cases, the findings are comparable to the ones of other types of breast tumors ${ }^{(10)}$. On mammography, as described by Ogawa et al. ${ }^{(1)}$, such tumors may present as well circumscribed lesions, with no associated microcalcifications, mimicking benign lesions. Such findings are in agreement with the ones observed in the present case, where the lesion corresponded to a well defined mass of medium density and with no associated microcalcifications. On ultrasonography, such tumors may present as either morphologically irregular solid lesions or lesions with a cystic component, with ill defined margins and increased vascularization $^{(1,4,5)}$. Also, in the present case, ultrasonography revealed the presence of a hypoechogenic mass with irregular morphology and ill defined contours, with no cystic component. MRI demonstrated, like in other cases described in the literature ${ }^{(4,5)}$, the presence of an irregular lesion with early, intense, ring-enhancement, with morphological and kinetic characteristics of contrast uptake consistent with malignancy.

Thus, despite the rarity of neuroendocrine carcinomas, with nonspecific imaging findings, such tumors should be included in the differential diagnosis of a nodular lesion with no associated microcalcifications on mammography and sonographically corresponding to a hypoechogenic mass with microlobulated or irregular contours.

\section{REFERENCES}

1. Ogawa H, Nishio A, Satake H, et al. Neuroendocrine tumor in the breast. Radiat Med. 2008;26:28-32.

2. Menéndez P, García E, Rabadán L, et al. Primary neuroendocrine breast carcinoma. Clin Breast Cancer. 2012;12:300-3.

3. Kinoshita S, Hirano A, Komine K, et al. Primary small-cell neuroendocrine carcinoma of the breast: report of a case. Surg Today. 2008;38:734-8.

4. Fujimoto Y, Yagyu R, Murase K, et al. A case of solid neuroendocrine carcinoma of the breast in a 40-year-old woman. Breast Cancer. 2007;14:250-3.

5. Günhan-Bilgen I, Zekioglu O, Ustün EE, et al. Neuroendocrine differentiated breast carcinoma: imaging features correlated with clinical and histopathological findings. Eur Radiol. 2003;13:788-93.

6. Nozoe T, Sueishi K, Mori E, et al. Primary neuroendocrine carcinoma of the breast: report of a case. Surg Today. 2011;41:829-31.

7. Kim JW, Woo OH, Cho KR, et al. Primary large cell neuroendocrine carcinoma of the breast: radiologic and pathologic findings. $\mathrm{J}$ Korean Med Sci. 2008;23:1118-20.

8. Gobbi H. Classificação dos tumores da mama: atualização baseada na nova classificação da Organização Mundial da Saúde de 2012. J Bras Patol Med Lab. 2012;48:463-74.

9. Graça S, Esteves J, Costa S, et al. Neuroendocrine breast cancer. BMJ Case Rep. 2012 Aug 13;2012.

10. Alkaied H, Harris K, Azab B, et al. Primary neuroendocrine breast cancer, how much do we know so far? Med Oncol. 2012;29:26138 . 